\title{
Jumping genes and AFLP maps: transforming lepidopteran color pattern genetics
}

\author{
Jeffrey M. Marcus \\ Department of Biology, Western Kentucky University, Bowling Green, KY 42101, USA \\ Correspondence: (email: jeffrey.marcus@wku.edu)
}

SUMMARY The color patterns on the wings of lepidopterans are among the most striking patterns in nature and have inspired diverse biological hypotheses such as the ecological role of aposomatic coloration, the evolution of mimicry, the role of human activities in industrial melanism, and the developmental basis of phenotypic plasticity. Yet, the developmental mechanisms underlying color pattern development are not well understood for three reasons. First, few mutations that alter color patterns have been characterized at the molecular level, so there is little mechanistic understanding of how mutant phenotypes are produced. Second, although gene expression patterns resembling adult color patterns are suggestive, there are few data available showing that gene products have a functional role in color pattern formation. Finally, because with few exceptions (notably Bombyx), genetic maps for most species of Lepidoptera are rudimentary or nonexistent, it is very difficult to characterize spontaneous mutants or to determine whether mutations with similar phenotypes are because of lesions in the same gene or different genes. Discussed here are two strategies for overcoming these difficulties: germ-line transformation of lepidopteran species using transposon vectors and amplified frequency length polymorphism-based genetic mapping using variation between divergent strains within a species or between closely related and interfertile species. These advances, taken together, will create new opportunities for the characterization of existing genetic variants, the creation of new sequencetagged mutants, and the testing of proposed functional genetic relationships between gene products, and will greatly facilitate our understanding of the evolution and development of lepidopteran color patterns.

\section{INTRODUCTION}

Lepidopteran wing color patterns are among the most attractive model systems for exploring the relationship between development and evolution. They are interesting evolutionarily because at least some patterns are clearly associated with fitness benefits associated with natural or sexual selection, playing roles in the evolution of mimicry (Clarke and Sheppard 1960), the phenomenon of industrial melanism (Kettlewell 1973), the development of aposematic coloration (Brower 1958), and the manifestation of phenotypic plasticity (Windig 1994). These patterns are also particularly suitable for study because they are highly variable, consist of clearly defined subunits, exist in two dimensions, and are structurally simple (Nijhout 1991; Brakefield 1996; Beldade and Brakefield 2002).

For these reasons, many researchers with interests in modeling developmental processes have studied butterfly color patterns. Early models used generalized mechanisms of pattern formation (e.g., lateral inhibition, reaction-diffusion, diffusion gradient, and threshold responses) to make predictions about how color patterns will vary as parameters of the model are changed. Such models have been used as the basis for simulations of the microevolution of color patterns (Nijhout and Paulsen 1997), for understanding fluctuating asymmetry in terms of classical quantitative genetic theory (Klingenberg and Nijhout 1999), to test the suitability of proposed groundplans as a basis for understanding the evolution of pattern polymorphisms (Sekimura et al. 2000), and to understand the responses of wing patterns to surgical perturbations (Brakefield and French 1995; French and Brakefield 1995; Monteiro et al. 2001).

Some of the more recent models propose regulatory interactions between specific gene products to account for the differentiation of particular color patterns (Fig. 1). The genetic hierarchies proposed by these models have been used to explain phenomena such as the formation of eyespots (Brakefield et al. 1996; Brunetti et al. 2001), melanic polymorphisms in butterflies (Koch et al. 1998), scale formation (Reed 2004), and the conservation of regulatory networks and their cooption for different functions across species (Keys et al. 1999). These genetic models have relied heavily on the study of expression patterns of candidate genes identified primarily from Drosophila melanogaster and with only a few exceptions (Lewis et al. 1999; Weatherbee et al. 1999), gene products 
thought to be involved in patterning the butterfly wing are implicated on the basis of a suggestive expression pattern that coincides with the shape and location of a color pattern element (Carroll et al. 1994; Weatherbee and Carroll 1999; Brunetti et al. 2001).

Some of the most convincing data on lepidopteran color pattern development comes from comparative studies of different species (Carroll et al. 1994; Brunetti et al. 2001), of phenotypically differentiated laboratory strains (Beldade et al. 2002), or of spontaneously occurring mutants within a species (Brakefield et al. 1996) that correlate changes in gene expression with changes in color pattern. However, the experimental manipulation of gene expression in butterflies has proven to be difficult, and to date the only gene product with a known

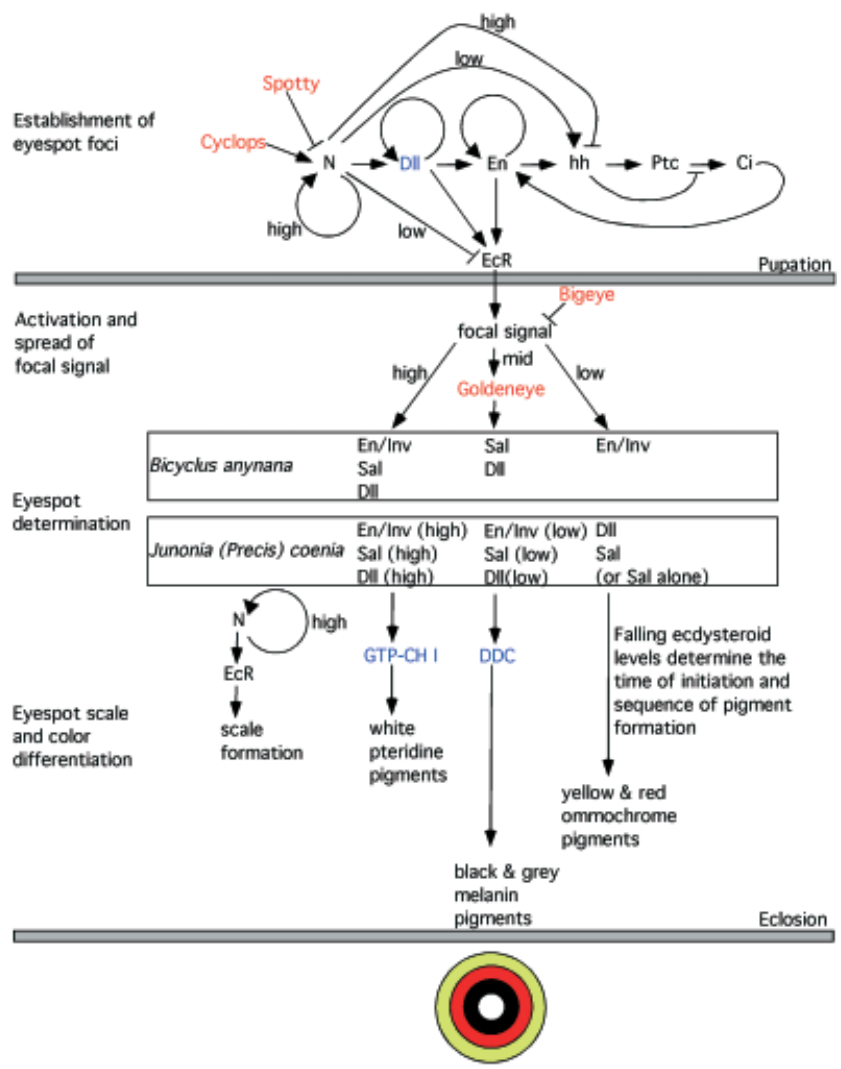

Fig. 1. Developmental model for the formation of butterfly eyespots (also known as border ocelli). Genes labeled in red are spontaneous mutants that appear to function in color pattern development, but that have not been characterized at the molecular level. The inferred role of these mutations is based on the assumption that these are loss-of-function mutations. Genes labeled in blue are candidate genes for which data other than gene expression pattern are available to support their role in color pattern formation. All of the other genes and genetic interactions shown on this diagram are inferred only from gene expression data and knowledge about genetic interactions from other model systems. Eyespot development can be broken down into several stages (Brakefield et al. 1996; Nijhout 1996). First, the number and position of eyespot foci are established. Next, it is hypothesized that a function for which there are functional data supporting its inferred role in wing pattern determination in butterflies is Ultrabithorax (Lewis et al. 1999; Weatherbee et al. 1999). There is also some functional data for enzymes involved in the differentiation of butterfly color patterns, particularly for DOPA decarboxylase (Koch 1995; Koch and Kaufmann 1995) and GTP cyclohydrolase I (Sawada et al. 2002).

It has also been difficult to map spontaneous color pattern mutants genetically and to describe them molecularly. To date, in spite of the considerable effort spent in generating collections of strains with color pattern variations (Koch et al. 1998, 2000; Weatherbee et al. 1999; Brakefield 2001; Koch and Nijhout 2002; McMillan et al. 2002; Monteiro et al. 2003), there are no reports of lepidopteran color pattern genes being characterized by positional cloning, and the only color pattern variants that have been characterized at the molecular level thus far have been analyzed via a candidate gene approach (Beldade et al. 2002).

Much of the data are from genes with known function (at least in Drosophila), but without known phenotypic effects in the Lepidoptera, whereas the remainder have known phenotypic effects, but no known function, greatly restricting further progress in understanding the development of color patterns. As a result, the reported interactions between gene products involved in color pattern development, such as those shown in Fig. 1, remain highly speculative. Clearly, there is a great need for techniques that will permit the routine in vivo manipulation of expression patterns and for methods that will facilitate the molecular description of genetic color pattern variants. The two techniques described in this paper, transposon-mediated germ-line transformation and amplified frequency length polymorphism (AFLP)-based genetic mapping,

focal signal is secreted from the eyespot focus and that patterns the surrounding tissue (French and Brakefield 1995). The molecular identity of the focal signal has not been determined. The rings of the eyespot are then determined in response to different concentrations of the focal signal. Eyespot determination may involve different gene products in different butterfly species - the known expression patterns of genes in the eyespots of the two most thoroughly studied species Bicyclus anynana and Junonia (Precis) coenia are shown. Finally, the wing scales that contain the pigment differentiate and the pigment molecules are synthesized in response to falling ecdysteroid levels. White pteridine pigments are produced first, followed by yellow and red ommochromes, with black and gray melanin pigments being produced last (Nijhout 1980; Koch 1992). Abbreviations: N-Notch, Dll-Distalless, En-Engrailed, hhhedgehog, Ptc-Patched, Ci-Cubitus interruptus, EcR-Ecdysone receptor, Inv-Invected, Sal-Spalt, GTP-CH I-GTP cyclohydrolase I, DDC-DOPA Decarboxylase. Genetic interactions shown here have been previously reported in or are inferred from the literature (Koch and Nijhout 1990; Koch 1991, 1995; Nijhout and Koch 1991; Carroll et al. 1994; Koch and Kaufmann 1995; Brakefield et al. 1996; Keys et al. 1999; Koch et al. 2000, 2003; Brakefield 2001; Brunetti et al. 2001; Sawada et al. 2002; Reed 2004; Reed and Serfas 2004). 
may allow butterfly color pattern researchers to overcome some of these difficulties and will ultimately facilitate a much better understanding of the development and evolution of these striking color patterns.

\section{Transposon-mediated germ-line transformation}

There are now a number of methods available for the transient manipulation of gene expression in vivo. Several of these (RNAi, morpholinos, viral transfection) have been attempted in the Lepidoptera, but thus far, only viral transfection of misexpression constructs has been successful (Lewis et al. 1999). However, even this technique has not been widely adopted because the groups of transformed cells that are produced by viral transfection in butterflies tend to be so small that they are often uninformative.

An alternative strategy for manipulating gene expression is to introduce genetic constructs into the organism via a transposon vector, which then integrates into the germ line in a heritable fashion (Rubin and Spradling 1982). These vectors can be engineered to misexpress gene products in the entire organism, or in narrowly focused domains of expression (via laser-induced heat shock [Halfon et al. 1997] or tissue-specific enhancers [Brand and Perrimon 1993]) and the resulting experimental data used to make inferences about gene function. Transposon-mediated germ-line transformation also greatly facilitates the identification and characterization of novel genes with roles in a developmental process of interest. Genetic constructs carried by transposons can be used for insertional mutagenesis, in which there is selection for transposons that have interrupted genetic loci (Zhang and Spradling 1994). The interrupted loci are now tagged by the DNA sequence of the inserted transposon, so inverse PCR (Ochman et al. 1988) or plasmid rescue techniques (Hamilton et al. 1991) can be used to obtain the sequence of the DNA immediately adjacent to the insert, allowing the rapid molecular characterization of the interrupted locus. Transposonmediated germ-line transformation in Drosophila has also been used to facilitate several other experimental manipulations including the creation of mitotic clones (Golic and Lindquist 1989; Xu and Rubin 1993), the expression of epitope-tagged proteins (Dick et al. 1996), the characterization of promoter elements (Ludwig et al. 1998), the mapping of genes by traditional recombination mapping (Marcus 2003b), and the development of new genetic mapping techniques (Chen et al. 1998; Marcus 2003a).

In the past, progress in insect transformation has been limited by the fact that suitable transposons and selectable markers had to be identified for every species (Atkinson et al. 2001; Horn et al. 2002). Recently, the discovery of four different transposon vectors (mariner, Hermes, piggyBac, and Minos) that seem to effectively transpose and integrate in diverse groups of arthropods (Horn and Wimmer 2000;
Kapetanaki et al. 2002) and the creation of several selectable fluorescent markers (green fluorescent protein, GFP, its derivatives, and red fluorescent protein, DSRed) driven by promoters that work in many species such as the $3 \mathrm{xP} 3$ eyespecific (Berghammer et al. 1999) and the actin5C and BmA3 global promoters (Reichhart and Ferrandon 1998; Tamura et al. 2000) has created a set of tools that appear to be broadly transferable to diverse species of insects (Fig. 2).

These new transposon tools have been used successfully in the germ-line transformation of moths in the families Gelechiidae (Peloquin et al. 2000), Bombycidae (Tamura et al. 2000), and Pyralidae (O. P. Perera, personal communication), as well as in the transformation of Bicyclus anynana butterflies in the family Satyridae (Marcus et al. 2004). Research on B. anynana germ-line transformation continues in the laboratory of Antónia Monteiro. In my laboratory we are working to transform a second butterfly species, Junonia (Precis) coenia, the North American buckeye butterfly, in the family Nymphalidae. This will be useful because $J$. coenia is already among the most advanced butterfly model systems for understanding lepidopteran color patterns, with numerous gene expression patterns (Carroll et al. 1994; Keys et al. 1999) and mutants (Nijhout and Rountree 1995; Rountree and Nijhout 1995; Weatherbee et al. 1999) already described.

A particularly exciting advance will be the development of a system for transposon-based insertional mutagenesis in the Lepidoptera. Such a system requires strains carrying genetically stable sources of transposase and strains that carry marked mobilizable transposable elements that can be crossed and screened under controlled conditions. Initially developed in Drosophila using a disabled P-element that could not transpose, but that had a functional transposase gene (Cooley et al. 1988), this strategy has been generalized by placing the transposase coding sequence of one transposon into a vector of another transposon type that is not cross-mobilized by the transposase. This has allowed the creation of stable sources of transposase on multiple chromosomes in Drosophila (Calvi
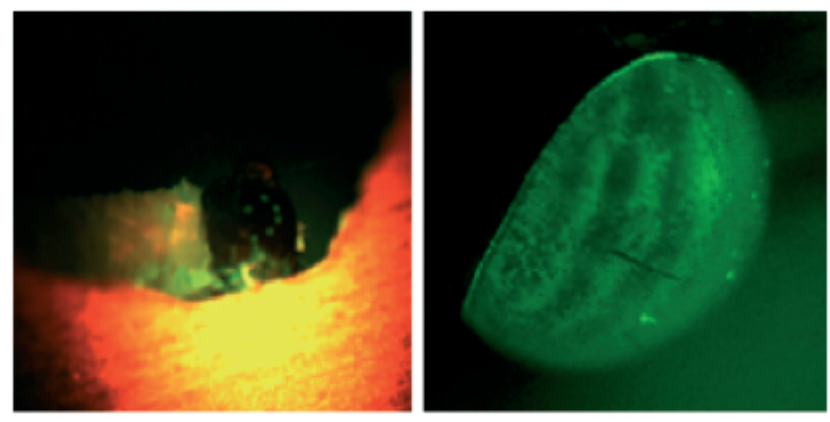

Fig. 2. Larval stemmata (left) and adult compound eye (right) of Bicyclus anynana expressing green fluorescent protein under the control of the $3 \mathrm{xP} 3$ promoter (Berghammer et al. 1999; Marcus et al. 2004). Red fluorescence in the larval image is from plant material on which the larva is feeding or that the larva has ingested. 
1993; Rollins et al. 1999) and the creation of genetically stable sources of transposase in the beetle Tribolium castaneum (Lorenzen et al. 2003). These mutagenesis tools are now being adapted for use in the silkworm Bombyx mori in the laboratory of Toshiki Tamura and in my laboratory for use in the butterfly $J$. coenia. As protocols for lepidopteran transformation become standardized, as vectors and selectable markers improve, and as transformation efficiencies increase, germ-line transformation may become a more generally useful technique in a number of butterfly species.

\section{AFLP mapping}

Whereas transposon-based mutagenesis generates new mutations that can be easily characterized by sequencing flanking regions, it is less useful for characterizing the spontaneous color pattern mutants that are already available. At the moment, it is extremely difficult to determine whether butterfly mutations with similar phenotypes are alleles at a single locus, or whether they are mutations at different loci that happen to have a similar mutant phenotype (Monteiro et al. 2003). Positional cloning techniques that would allow us to distinguish between these alternatives and also permit the characterization of these mutants require the development of high-resolution genetic maps. Such a map is already available in the silkworm Bombyx mori (Yasukochi 1998), but unfortunately, B. mori has indistinct color patterns on its wings, and there are few mutations available from the stock collections that alter what patterns are present.

A recent innovation in mapping lepidopteran genomes has been to use two closely related species (or two highly divergent strains within a species) that are distinct, but that can produce fertile hybrid offspring. Any pair of sister taxa that do not interbreed in the wild will accumulate silent mutations over time that will help to make the pair increasingly distinct from one another, and if the pair can produce fertile hybrids these differences can be tracked in a genetic cross and used to create a genetic map. Amplified frequency length polymorphisms (AFLPs) markers (Vos et al. 1995) are convenient molecular markers to use for creating genetic maps and for identifying chromosome intervals that contain genes that influence traits of interest. These analyses are facilitated by the biphasic nature of lepidopteran genetic linkage: whereas genetic segregation takes place in both male and female Lepidoptera, genetic recombination only takes place in male Lepidoptera (Suomalainen et al. 1973; Goldsmith and Wilkins 1995; Heckel et al. 1999). Therefore, females will transmit entire chromosomes to their offspring as a single unit, making the determination of linkage groups very simple, whereas males will undergo recombination, so genetic distances between loci within a linkage group can also be easily determined (Fig. 3). This technique has already been used successfully to map and identify genes associated with pesti-

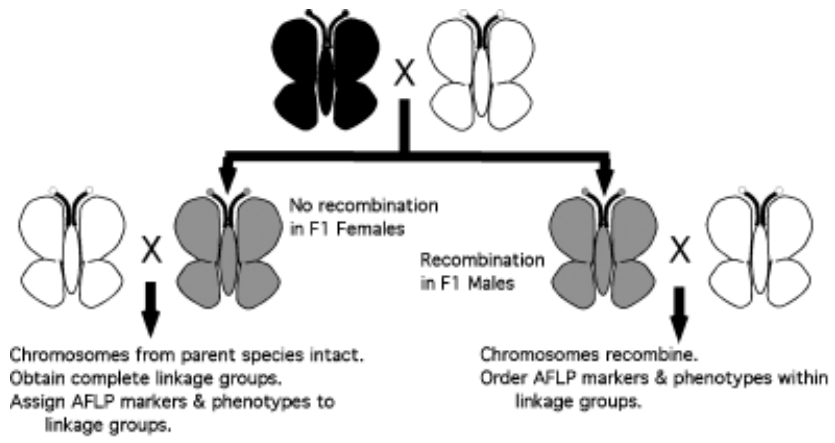

Fig. 3. Amplified frequency length polymorphism mapping scheme that utilizes two parental species (in white and black) that are capable of producing fertile hybrids (in gray). F1 hybrid progeny are backcrossed to one of the parental species via reciprocal crosses to take advantage of the fact that there is segregation, but no recombination in female Lepidoptera, allowing the easy identification of linkage groups, whereas there is both segregation and recombination in male Lepidoptera, allowing the order of the markers within a linkage group to be determined (Heckel et al. 1998, 1999).

cide resistance (Heckel et al. 1998, 1999) and sexual isolation (Dopman et al. 2004) in several species of moths.

Apparently, a number of researchers interested in butterfly color pattern genetics became aware of this technique independently, and at about the same time, because AFLP-based genetic maps are currently being constructed by crosses among races of Heliconius numata (by Mathieu Joron and James Mallet), between Papilio glaucus and P. canadensis (by Makiri Sei and Adam Porter), between Colias philodice and C. eurytheme (by Baiqing Wang and Adam Porter), and between Junonia coenia and $J$. evarete (in my laboratory). There is also a project to recombination map EST polymorphisms in crosses among genetically divergent strains of $B$. anynana (by Patrícia Beldade, Tony Long, and Paul Brakefield). Butterfly color pattern genetics, once largely uncharted territory, is about to be covered by an unprecedented number of genetic maps.

The first groups to publish AFLP-based genetic maps for butterflies are two consortia of Heliconius researchers (Jiggins et al. in press; Tobler et al. in press). Tobler et al. (in press) mated a male Heliconius erato to a female H. himera, and then took sibling male and female interspecific F1 hybrids and mated them back to H. himera. Using AFLP markers and several single copy nuclear loci, Tobler et al. (in press) have been able to identify all 21 linkage groups of $H$. erato and to construct recombination maps for 19 of the 21 groups. They were able to assign two wing color pattern loci to linkage groups: $\mathrm{Cr}$ to a $74 \mathrm{cM}$ interval on linkage group 2 and $\mathrm{D}$ to a position on linkage group 3 that is maximally distant to the other markers that co-segregate with it. Jiggins et al. (in press) used an F2 cross design between Heliconius melpomene melpomene and $H$. m. cythera and a combination of AFLP markers, microsatellites, and single copy genes, to recover 
linkage groups and recombination maps for all 21 chromosome pairs in this species. They were also able to determine that two-color pattern loci $\mathrm{Yb}$ and $\mathrm{Sb}$ are linked and only 1.3 $\mathrm{cM}$ apart, and that $\mathrm{Yb}$ appears to be within $1 \mathrm{cM}$ of the nearest AFLP locus in linkage group 15.

Although most of the reported genetic intervals are still too large for easy positional cloning of color pattern variants, as the density of marker loci on these genetic maps increases, it may be possible to use these markers as starting points for chromosome walks. However, in the shorter term, even coarse genetic maps are useful for assigning variants to specific autosomal linkage groups and testing hypotheses of allelism between genetic variants with similar phenotypes, a task that has been very difficult in butterflies in the past.

\section{CONCLUSIONS}

Research in lepidopteran color pattern evolution and development is on the verge of entering a new and exciting phase. Although descriptive studies of gene expression patterns in developing lepidopteran wings will doubtless continue to be published (and in this age of inexpensive genome sequencing and array-based expression studies, probably published at a rate greater than ever before), the hypothesized genetic interactions and mechanisms of determination and differentiation based on these expression patterns may soon, finally, be testable.

It appears that in the near future, both germ-line transformation and AFLP mapping may become available in at least two different butterfly model species (B. anynana and $J$. coenia). These two techniques in combination provide opportunities to characterize existing phenotypic variation and spontaneous mutations by positional cloning, the testing of proposed functional genetic interactions by misexpression of candidate gene products, and the discovery of new genes involved in color pattern formation by mutagenesis. Having both techniques available in two butterfly model systems will greatly facilitate comparisons between the developmental genetic architecture underlying color pattern formation, and allow inferences to be made about the evolution of development of these patterns.

Soon, it may even be possible to treat color patterns as sensitive marker phenotypes to study the basic cellular processes such as cell division and signal transduction that are necessary for color pattern formation. For example, there are stripes of wingless mRNA expression that appear to coincide with orange bars that appear on the forewing of Junonia butterflies (Carroll et al. 1994). Mutants that change the shape, size, or location of these orange bars might be associated with lesions in members of the wingless signal transduction pathway. As wingless is a conserved signal transduction pathway that has been found in organisms as diverse as hydra (Hobmayer et al. 2000) and humans (Wainwright et al. 1988), and in which aberrant signaling has been implicated in cancer formation in both mice (Rijsewijk et al. 1987) and humans (Hayashi et al. 1997; Lo Muzio 2001; Uthoff et al. 2001), any new members of this pathway identified in butterflies will be of broad general interest.

Finally, although color patterns have been the primary focus of this article, there are also other potentially interesting phenomena for which a lepidopteran genetic model system would be of particular utility. For example, although much is known about sex determination and dosage compensation in organisms with XY or XO sex determination (studies in flies, vertebrates, and worms), much less is known about organisms with WZ sex determination, and almost all of what is known about WZ sex determination is known from vertebrates. Some work has already been carried out as part of a consideration of Haldane's rule in Heliconius butterflies (Naisbit et al. 2002), but a careful study of WZ sex determination and dosage compensation in a lepidopteran species using an array of genetic techniques could make additional important contributions to our understanding of the generality of sexdetermining mechanisms.

\section{Acknowledgments}

I thank Laura Corley for organizing the Symposium: Understanding Microevolution and Development in the Arthropods at the 2004 International Congress of Entomology. Thanks are due to J. Seiff for her enduring love, support, and patience. This article is dedicated in memory of L. Seiff, whose good humor, devotion, and enthusiasm greatly enriched our lives. Tia Hughes, Amber Harper, Amanda Maupin, Brooke Polen, Tara Powell, and two anonymous reviewers provided helpful comments. Permission to collect Junonia (Precis) evarete in Florida was generously provided by the Florida Department of Environmental Protection (permit number 5-04-31). Support for this research is from the National Science Foundation and the Commonwealth of Kentucky through an EPSCoR award (EPS0132295), from the National Institutes of Health and the National Center for Research Resources (grant P20 RR16481), and from a Junior Faculty Scholarship from Western Kentucky University.

\section{REFERENCES}

Atkinson, P. W., Pinkerton, A. C., and O'Brochta, D. A. 2001. Genetic transformation systems in insects. Ann. Rev. Entomol. 46: 317-346.

Beldade, P., and Brakefield, P. M. 2002. The genetics and evo-devo of butterfly wing patterns. Nat. Rev. Genet. 3: 442-452.

Beldade, P., Brakefield, P., and Long, A. 2002. Contribution of Distal-less to quantitative variation in butterfly eyespots. Nature 415: 315-318.

Berghammer, A. J., Klingler, M., and Wimmer, E. A. 1999. Genetic techniques - a universal marker for transgenic insects. Nature 402: 370-371.

Brakefield, P. M. 1996. Seasonal polyphenism in butterflies and natural selection. Trends Ecol. Evol. 11: 275-277.

Brakefield, P. M. 2001. Structure of a character and the evolution of butterfly eyespot patterns. J. Exp. Zool. 291: 93-104.

Brakefield, P. M., and French, V. 1995. Eyespot development on butterfly wings: the epidermal response to damage. Dev. Biol. 168: 98-111.

Brakefield, P. M., et al. 1996. Development, plasticity and evolution of butterfly eyespot patterns. Nature 384: 236-242. 
Brand, A. H., and Perrimon, N. 1993. Targeted gene expression as a means of altering cell fates and generating dominant phenotypes. Development 118: 401-415.

Brower, J. V. Z. 1958. Experimental studies of mimicry in some North American butterflies. Part 1. The Monarch, Danaus plexippus, and Viceroy, Limenitis archippus archipus. Evolution 12: 32-47.

Brunetti, C. R., Selegue, J. E., Monteiro, A., French, V., Brakefield, P. M. and Carroll, S. B. 2001. The generation and diversification of butterfly eyespot colour patterns. Curr. Biol. 11: 1578-1585.

Calvi, B. R. 1993. The hobo transposable element in Drosophila: evolution, regulation, and use as a genetic tool. PhD Thesis, Harvard University, MA.

Carroll, S. B., et al. 1994. Pattern formation and eyespot determination in butterfly wings. Science 265: 109-114.

Chen, B., Chu, T., Harms, E., Gergen, J. P., and Strickland, S. 1998. Mapping of Drosophila mutations using site-specific male recombination. Genetics 149: 157-163.

Clarke, C. A., and Sheppard, P. M. 1960. The evolution of mimicry in the butterfly Papilio dardanus. Heredity 14: 163-173.

Cooley, L., Kelley, R., and Spradling, A. C. 1988. Insertional mutagenesis of the Drosophila genome with single P-elements. Science 239: 1121-1128

Dick, T., Ray, K., Salz, H. K., and Chia, W. 1996. Cytoplasmic dynein (ddlc1) mutations cause morphogenetic defects and apoptotic cell death in Drosophila melanogaster. Mol. Cell. Biol. 16: 1966-1977.

Dopman, E. B., Bogdanowicz, S. M., and Harrison, R. G. 2004. Genetic mapping of sexual isolation between $\mathrm{E}$ and $\mathrm{Z}$ pheromone strains of the European corn borer (Ostrina nubialis). Genetics 167: 301-309.

French, V., and Brakefield, P. M. 1995. Eyespot development on butterfly wings: the focal signal. Dev. Biol. 168: 112-123.

Goldsmith, M. R., and Wilkins, A. S. 1995. Molecular Model Systems in the Lepidoptera. Cambridge University Press, Cambridge, U.K.

Golic, K. G., and Lindquist, S. 1989. The FLP recombinase of yeast catalyzes site-specific recombination in the Drosophila genome. Cell 59: 499-509.

Halfon, M. S., Kose, H., Chiba, A., and Keshishian, H. 1997. Targeted gene expression without a tissue-specific promoter: creating mosaic embryos using laser-induced single-cell heat shock. Proc. Natl. Acad. Sci. USA 94: 6255-6260.

Hamilton, B. A., et al. 1991. Large scale screen for transposon insertions into cloned genes. Proc. Natl. Acad. Sci. USA 88: 2731-2735.

Hayashi, S., Rubinfeld, B., Souza, B., Polakis, P., Wieschaus, E., and Levine, A. J. 1997. A Drosophila homolog of the tumor suppressor gene adenomatous polyposis coli down-regulates beta-catenin but its zygotic expression is not essential for the regulation of Armadillo. Proc. Natl. Acad. Sci. USA 94: 242-247.

Heckel, D. G., Gahan, L. J., Daly, J. C., and Trowell, S. 1998. A genomic approach to understanding Heliothis and Helicoverpa resistance to chemical and biological insecticides. Philos. Trans. R. Soc. London Ser. B-Biol. Sci. 353: 1713-1722.

Heckel, D. G., Gahan, L. J., Liu, Y. B., and Tabashnik, B. E. 1999. Genetic mapping of resistance to Bacillus thuringiensis toxins in diamondback moth using biphasic linkage analysis. Proc. Natl. Acad. Sci. USA 96: 8373-8377.

Hobmayer, B., et al. 2000. WNT signalling molecules act in axis formation in the diploblastic metazoan Hydra. Nature 407: 186-189.

Horn, C., Schmid, B. G. M., Pogoda, F. S., and Wimmer, E. A. 2002 Fluorescent transformation markers for insect transgenesis. Insect Biochem. Mol. Biol. 32: 1211-1235.

Horn, C., and Wimmer, E. A. 2000. A versatile vector set for animal transgenesis. Dev. Genes Evol. 210: 630-637.

Jiggins, C. D., Mavarez, J., Beltrán, J., McMillan, W. O., Johnston, J. S., and Bermingham, E. In press. A genetic linkage map of the mimetic butterfly, Heliconius melpomene. Genetics 10.1534/genetics.104.034686.

Kapetanaki, M. G., Loukeris, T. G., Livadaras, I., and Savakis, C. 2002. High frequencies of Minos transposon mobilization are obtained in insects by using in vitro synthesized mRNA as a source of transposase. Nucleic Acids Res. 30: 3333-3340.

Kettlewell, B. 1973. The Evolution of Melanism: The Study of a Recurring Necessity. Oxford University Press, Oxford.
Keys, D. N., et al. 1999. Recruitment of a hedgehog regulatory circuit in butterfly eyespot evolution. Science 283: 532-534.

Klingenberg, C. P., and Nijhout, H. F. 1999. Genetics of fluctuating asymmetry: a developmental model of developmental instability. Evolution 53: 358-375

Koch, P. B. 1991. Precursors of pattern specific ommatin in red wing scales of the polyphenic butterfly Araschnia levana L.: haemolymph tryptophan and 3-hydroxykynurenine. Insect Biochem. 21: 785-794.

Koch, P. B. 1992. Seasonal polyphenism in butterflies: a hormonally controlled phenomenon of pattern formation. Zool. Jb. Physiol. 96 227-240.

Koch, P. B. 1995. Colour pattern specific melanin synthesis is controlled by ecdysteroids via dopa decarboxylase in wings of Precis coenia (Lepidoptera: Nymphalidae). Eur. J. Entomol. 92: 161-167.

Koch, P. B., and Kaufmann, N. 1995. Pattern specific melanin synthesis and DOPA decarboxylase activity in a butterfly wing of Precis coenia Hubner. Insect Biochem. Mol. Biol. 25: 73-82.

Koch, P. B., et al. 1998. Regulation of DOPA decarboxylase expression during colour pattern formation in wild-type and melanic swallowtail butterflies. Development 125: 2303-2313.

Koch, P. B., Lorenz, U., Brakefield, P. M., and ffrench-Constant, R. H. 2000. Butterfly wing pattern mutants: developmental heterochrony and co-ordinately regulated phenotypes. Dev. Genes Evol. 210: 536-544.

Koch, P. B., Merk, R., Reinhardt, R., and Weber, P. 2003. Localization of ecdysone receptor protein during colour pattern formation in wings of the butterfly Precis coenia (Lepidoptera: Nymphalidae) and co-expression with Distal-less protein. Dev. Genes Evol. 212: 571-584.

Koch, P. B., and Nijhout, H. F. 1990. Color pattern specific proteins in black scales in developing wings of Precis coenia Hubner (Nymphalidae, Lepidoptera). Roux's Arch. Dev. Biol. 199: 289-294.

Koch, P. B., and Nijhout, H. F. 2002. The role of wing veins in colour pattern development in the butterfly Papilio xuthus (Lepidoptera: Papilionidae). Eur. J. Entomol. 99: 67-72.

Lewis, D. L., et al. 1999. Ectopic gene expression and homeotic transformations in arthropods using recombinant Sindbis viruses. Curr. Biol. 9: 1279-1287.

Lo Muzio, L. 2001. A possible role for the WNT-1 pathway in oral carcinogenesis. Crit. Rev. Oral Biol. Med. 12: 152-165.

Lorenzen, M. D., Berghammer, A. J., Brown, S. J., Denell, R. E., Klingler, M., and Beeman, R. W. 2003. piggyBac-mediated germline transformation in the beetle Tribolium castaneum. Insect Mol. Biol. 12: 433-440.

Ludwig, M., Patel, N., and Kreitman, M. 1998. Functional analysis of eve stripe 2 enhancer evolution in Drosophila: rules governing conservation and change. Development 125: 949-958.

Marcus, J. M. 2003a. Female site-specific transposase induced recombination (FaSSTIR): a new high-efficiency method for fine-mapping mutations on the X-chromosome in Drosophila. Genetics 163: 591-597.

Marcus, J. M. 2003b. Recombination mapping of P-element transposon inserts: a new set of laboratory exercises for an undergraduate genetics course. Dros. Inf. Serv. 86: 168-171.

Marcus, J. M., Ramos, D. M., and Monteiro, A. 2004. Transformation of the butterfly Bicyclus anynana. Proc. R. Soc. B. Biol. Lett. 27: (suppl.) 263-265.

McMillan, W. O., Monteiro, A., and Kapan, D. D. 2002. Development and evolution on the wing. Trends Ecol. Evol. 17: 125-133.

Monteiro, A., French, V., Smit, G., Brakefield, P. M., and Metz, J. A. J. 2001. Butterfly eyespot patterns: evidence for specification by a morphogen diffusion gradient. Acta Biotheor. 49: 77-88.

Monteiro, A., Prijs, J., Hakkaart, T., Bax, M., and Brakefield, P. M. 2003. Mutants highlight the modular control of butterfly eyespot patterns Evol. Dev. 5: 180-187.

Naisbit, R. E., Jiggins, C. D., Linares, M., Salazar, C., and Mallet, J. 2002. Hybrid sterility, Haldane's rule and speciation in Heliconius cydno and H. melpomene. Genetics 161: 1517-1526.

Nijhout, H. F. 1980. Ontogeny of the color pattern on the wings of Precis coenia (Lepidoptera: Nymphalidae). Dev. Biol. 80: 275-288.

Nijhout, H. F. 1991. The Development and Evolution of Butterfly Wing Patterns. Smithsonian Institution Press, Washington, DC.

Nijhout, H. F. 1996. Focus on butterfly eyespot development. Nature 384: 209-210. 
Nijhout, H. F., and Koch, P. B. 1991. The distribution of radiolabeled pigment precursors in the wing patterns of nymphalid butterflies. J. Res. Lep. 30: 1-13.

Nijhout, H. F., and Paulsen, S. M. 1997. Developmental models and polygenic characters. Am. Nat. 149: 394-405.

Nijhout, H. F., and Rountree, D. B. 1995. Pattern induction across a homeotic boundary in the wings of Precis coenia (Lepidoptera: Nymphalidae). Int. J. Insect Morphol. Embryol. 24: 243-251.

Ochman, H., Gerber, A. S., and Hartl, D. L. 1988. Genetic applications of an inverse polymerase chain-reaction. Genetics 120: 621-623.

Peloquin, J. J., Thibault, S. T., Staten, R., and Miller, T. A. 2000. Germ-line transformation of pink bollworm (Lepidoptera: Gelechiidae) mediated by the piggyBac transposable element. Insect Mol. Biol. 9: 323-333.

Reed, R. D. 2004. Evidence for Notch-mediated lateral inhibition in organizing butterfly wing scales. Dev. Genes Evol. 214: 43-46.

Reed, R. D., and Serfas, M. S. 2004. Butterfly wing pattern evolution is associated with changes in a notch/distal-less temporal pattern formation process. Curr. Biol. 14: 1159-1166.

Reichhart, J. M., and Ferrandon, D. 1998. Green balancers. Dros. Inf. Serv. 81: 201-202.

Rijsewijk, F., Schuermann, M., Wagenaar, E., Parren, P., Weigel, D., and Nusse, R. 1987. The Drosophila homolog of the mouse mammary oncogene int-1 is identical to the segment polarity gene wingless. Cell 50: 649-657.

Rollins, R. A., Morcillo, P., and Dorsett, D. 1999. Nipped-B, a Drosophila homologue of chromosomal adherins, participates in activation by remote enhancers in the cut and Ultrabithorax genes. Genetics 152: 577-593.

Rountree, D. B., and Nijhout, H. F. 1995. Genetic control of a seasonal morph in Precis coenia (Lepidoptera: Nymphalidae). J. Insect Physiol. 41: 1141-1145.

Rubin, G. M., and Spradling, A. C. 1982. Genetic transformation of Drosophila with transposable element vectors. Science 218: 348-353.

Sawada, H., Nakagoshi, M., Reinhardt, R. K., Ziegler, I., and Koch, P. B. 2002. Hormonal control of GTP cyclohydrolase I gene expression and enzyme activity during color pattern development in wings of Precis coenia. Insect Biochem. Mol. Biol. 32: 609-615.
Sekimura, T., Madzvamuse, A., Wathen, A. J., and Maini, P. K. 2000. A model for colour pattern formation in the butterfly wing of Papilio dardanus. Proc. R. Soc. London B. 267: 851-859.

Suomalainen, E., Cook, L. M., and Turner, J. R. G. 1973. Achiasmatic oogenesis in the heliconiine butterflies. Hereditas 74: 302-304.

Tamura, T., et al. 2000. Germline transformation of the silkworm Bombyx mori L. using a piggyBac transposon-derived vector. Nat. Biotechnol. 18: 81-84.

Tobler, A., Flanagan, N., Jiggins, C. D., Heckel, D. G., Kapan, D. D., and McMillan, W. O. In press. A genetic map of microsatellite, AFLP, allozyme and colour pattern genes in Heliconius erato. Heredity 10.1038 sj.hdy. 6800619 .

Uthoff, S. M. S., Eichenberger, M. R., McAuliffe, T. L., Hamilton, C. J., and Galandiuk, S. 2001. Wingless-type frizzled protein receptor signaling and its putative role in human colon cancer. Mol. Carcinog. 31: $56-62$.

Vos, P., et al. 1995. AFLP: a new technique for DNA fingerprinting. $\mathrm{Nu}$ cleic Acids Res. 23: 4407-4414.

Wainwright, B. J., et al. 1988. Isolation of a human-gene with proteinsequence similarity to human and murine Int-1 and the Drosophila segment polarity mutant wingless. EMBO J. 7: 1743-1748.

Weatherbee, S. D., and Carroll, S. B. 1999. Selector genes and limb identity in arthropods and vertebrates. Cell 97: 283-286.

Weatherbee, S. D., et al. 1999. Ultrabithorax function in butterfly wings and the evolution of insect wing patterns. Curr. Biol. 9: 109-115.

Windig, J. J. 1994. Reaction norms and the genetic basis of phenotypic plasticity in the wing pattern of the butterfly Bicyclus anynana. J. Evol. Biol. 7: 665-695.

Xu, T., and Rubin, G. M. 1993. Analysis of genetic mosaics in developing and adult Drosophila tissues. Development 117: 1223-1237.

Yasukochi, Y. 1998. A dense genetic map of the silkworm, Bombyx mori, covering all chromosomes based on 1018 molecular markers. Genetics 150: $1513-1525$.

Zhang, P., and Spradling, A. C. 1994. Insertional mutagenesis of Drosophila heterochromatin with single P elements. Proc. Natl. Acad. Sci. USA 91: 3539-3543. 